\title{
Complete Avulsion of the Hoof Capsule and Subsequent Testicular Degeneration in a Criollo Stallion
}

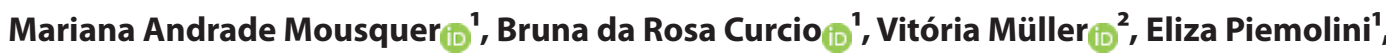 \\ Camila Gervini Wendt $\mathbb{D}^{1}$ \& Carlos Eduardo Wayne Nogueira $\mathbb{i}^{\prime}$
}

\begin{abstract}
Background: Complete avulsion of the hoof in horses, also known as exungulation, is not a commonly reported injury and usually leads to euthanasia due to the great amount of tissue loss, intense pain, secondary complications, expensive and lengthy treatment. It can involve deep structures and cause different complications leading to chronic lameness. In stallions affected by such injury, the reproductive tract and performance may also be affected. The aim of this study was to report a case of complete avulsion of the right front hoof in a Criollo stallion and subsequent bilateral testicular degeneration. Case: A 10-year-old Criollo stallion was referred to the Veterinary Clinical Hospital of the Federal University of Pelotas (HCV- UFPel) with a complete avulsion of the left front hoof. At admission, the stallion had clinical parameters compatible with intense pain and blood loss. Evaluation of the wound demonstrated that the distal end of the third phalanx (P3) was exposed but no fracture was detected on radiological evaluation. No other structure was apparently affected. Initially, anti-inflammatory (phenylbutazone) and opioid (morphine) was given for pain control and supportive fluid therapy was started to restore hydration. Antibiotic (Sulfamethoxazole with trimethoprim) was administered for 10 days. Continued therapy with phenylbutazone, pentoxifylline, omeprazole and supplementation with methionine, biotin and zinc was also given. Local treatment was carried out by cleaning the wound, applying an antimicrobial ointment and dressing it with a bandage. Wound management was adapted according to the evolution and healing process. The stallion was kept in stall rest during its hospitalization time. In the second month after the injury, accumulation of liquid in the scrotum was observed. Clinical and ultrasound evaluation lead to a presumptive diagnosis of testicular degeneration. The stallion was discharged after three months when the wound was almost healed and the hoof had started to grow. Six month later, a follow up by the referring vet showed that the hoof was almost completely grown and the x-ray assessment demonstrated a dorsal rotation and resorption of the distal end of the third phalanx.

Discussion: The stallion of this report had a complete avulsion of the hoof capsule caused by trauma. Conservative treatment was established including wound cleaning and dressing to avoid contamination, control of pain and inflammation, antimicrobial care and supplementation to support hoof growth. Time period for wound healing and hoof growth was in agreement with other cases described previously. Bone sequestrum of the distal end of the third phalanx, and detachment of a fragment were observed in this case, followed by bone resorption. The stallion was closely monitored to prevent laminitis in the contralateral limb and no alterations were detected during the treatment period. Testicular degeneration was observed, probably caused as a consequence of hoof avulsion and due to a long period of stall rest. Degenerative alterations in testicles interfere with thermoregulation and spermatogenesis, affecting semen quality and reproductive performance. Rotation of the third phalanx was also observed six months later caused by the hoof loss. In conclusion, the patient of this report had a complete regrowth of the hoof capsule although a long intensive treatment was necessary to achieve this result. As a consequence, testicles degeneration may happen impairing its function as a stallion.
\end{abstract}

Keywords: exungulation, hoof trauma, degenerative changes. 


\section{INTRODUCTION}

Complete avulsion of the hoof in horses may limit function, interfere with performance and euthanasia may be advised in some cases [20]. It is a relatively atypical injury with just few reports on literature [9$11,18]$. The origin can be traumatic or can be caused by traumatic, septic or inflammatory alterations in the coronary band. Even when significant loss of germinal tissue occurs, the foot has the capacity to heal with establishment of proper treatment, although slower than other tissues [20].

This injury can involve different and deep structures in the hoof capsule. Implication of deep structures should be evaluated by clinical and imaging exams [19]. Osteomyelitis, distal phalanx fractures, septic arthritis and degenerative disease are common complications [20]. Treatment is lengthy and expensive and the prognosis is guarded to poor $[18,20]$.

In addition, when such injury occurs in stallions, it is a concern to preserve reproductive performance. Musculoskeletal disorders and long periods of stall rest can lead to development of testicular degeneration $[3,6]$. Testicular degeneration is the main cause of subfertility and infertility $[3,23]$. It has multifactorial causes, however, alteration in testicular thermoregulation is known as the main triggering factor [1,3]. Depending on the cause and the exposure time, the degeneration can also vary as temporary or permanent [6].

Therefore, the aim of this study was to report a case of complete avulsion of the right front hoof in a Criollo stallion and subsequent bilateral testicular degeneration. To the best of our knowledge this is the first report of a front hoof exungulation in a Criollo stallion.

\section{CASE}

A 10-year-old Criollo stallion was referred to the Veterinary Clinical Hospital of the Federal University of Pelotas (HCV- UFPel) during the breeding season. The horse presented a complete avulsion of the left front hoof with third phalanx exposure due to a wire fence accident (Figure 1).

At admission, the stallion was alert, demonstrating intense pain and non-weight-bearing lameness. At the initial clinical exam, the heart rate (HR) was 100 $\mathrm{bpm}$, respiratory rate (RR) was $60 \mathrm{bpm}$, body temperature was $39^{\circ} \mathrm{C}$, mucous membranes were pale with a capillary refill time (CRT) of $4 \mathrm{~s}$, intestinal sounds were diminished in all quadrants and dehydration was estimated in $10 \%$. Hematologic evaluation revealed anemia and neutrophilic leukocytosis. Closely evaluation of the wound revealed that the distal end of the third phalanx (P3) was exposed. Radiographic evaluation was performed and, besides exposure of P3, no fracture was identified and no other structure was apparently affected.

Phenylbutazone $^{1}$ [Fenilbutazona OF - $4.4 \mathrm{mg} /$ $\mathrm{kg}$, IV] and morphine ${ }^{2}$ [Dimorf - $0.2 \mathrm{mg} / \mathrm{kg}$, IV] were administered initially to manage pain. Support fluid therapy was given to restore hydration. Sulfamethoxazole with trimethoprim ${ }^{3}$ [Borgal - $15 \mathrm{mg} / \mathrm{kg}$, IV, q $12 \mathrm{~h}$ ] was given for 10 days, phenylbutazone ${ }^{4}$ [Equipalazone pó - $2.2 \mathrm{mg} / \mathrm{kg}$, PO] was administered as needed and omeprazole $^{5}$ [Omeprazol - 5 mg/kg, PO, q 24 h] were continued for 30 days. Pentoxifylline ${ }^{5}$ [Pentoxilifina $7,5 \mathrm{mg} / \mathrm{kg}, \mathrm{PO}, \mathrm{q} 12 \mathrm{~h}$ ] was associated on the seventh day and was given for 30 days. Wound treatment was also performed daily by cleansing the wound with water, drying it and applying nitrofurazone ointment ${ }^{5}$ (nitrofurazona). A bandage made with cotton and gauze or a diaper was put to prevent dirt from entering. In the first month of treatment, there was an improvement in the healing process and the patient was already able to support the limb on the ground (Figure 2A). Detachment of the distal end of the third phalanx was also observed and the fragment was removed.

After 2 months, local treatment was adapted due to the improvement in the healing process (Figure 2B). The foot started to be soaked in a diluted povidone iodine solution ${ }^{6}$ (Riodeine 0,2\%) and petroleum jelly ${ }^{5}$ (Vaselina) was applied around the wound, the same dressing was continued. Supplementation with biotin, methionine and zinc ${ }^{7}$ [Bio Hoof - 20 g/day, PO] was given during all hospitalization time. During all the treatment, the stallion was maintained in stall rest, with a high rice husk bed. The horse was able to alternate its position from recumbent to standing by itself.

In the second month of hospitalization, accumulation of liquid in the scrotum was observed. The testicles were palpated and a softening in the consistency of both testicles was identified. No alterations on size and position were observed. Ultrasound revealed a hydrocele and no other abnormalities were found. Two attempts to collect semen were made using an artificial vagina and two different mares in heat, but failed because the horse did not have libido. Pharmacological induction of ejaculation was also tried 
but it was not successful. A presumptive diagnosis of testicular degeneration was made based on clinical evaluation. Testicular biopsy was not performed to confirm the diagnosis.

Three months later, the stallion was discharged since the wound was almost healed and the hoof had grown $1.3 \mathrm{~cm}$ (Figure 2C). The owner was advised to continue wound dressing and veterinary monitoring at home. Six months later, the referring veterinarian reported that the hoof was almost completely grown and radiograph evaluation showed resorption of the distal end of the third phalanx and rotation.

\section{DISCUSSION}

The patient of this report had a complete avulsion of the hoof capsule caused by trauma. Although intensive and lengthy therapy had to be established and the patient developed testicular degeneration, it had a successful recovery with complete hoof regrowth.

The hoof wall is responsible for supporting the horse's weight and absorption of shock when contacting the ground [7]. The epithelium of the hoof is composed of three recognized layers: the stratum basale, stratum spinosum and stratum corneum in which the stratum basale and stratum spinosum constitute the stratum germinativum [15]. The hoof wall growth occurs from the stratum germinativum of the coronary corium and reached approximately $6-10 \mathrm{~mm}$ per month [8,21]. In our patient, the hoof reached $1.3 \mathrm{~cm}$ during the 3-month period in which the horse was hospitalized.

In the case reported here, the time for wound healing (3 months) and hoof growth (6 months) was in agreement with the time reported in the literature $[8,20]$. According to Fessler [8] and Stashak [20], it takes generally 3 to 5 months to heal and 9 to 12 months to the complete growth of a new hoof. Other reports describe a complete growth of a new hoof capsule in a period of 4 [11] and 6 [10] months.

The ground proximity of this injury also increases the risks of contamination and delay healing. Therefore, protection of the wound with either a bandage or a cast is recommended $[17,20]$. Conservative treatment instituted in this case was similar to those described before [8,22], including soaking the foot in antiseptic solutions, wound bandaging changed regularly to monitor possible local infections and maintenance of the horse in high bed stalls to improve its comfort. The use of a rigid cast is also recommended in order to accelerate the healing process and weight bearing [10,20].

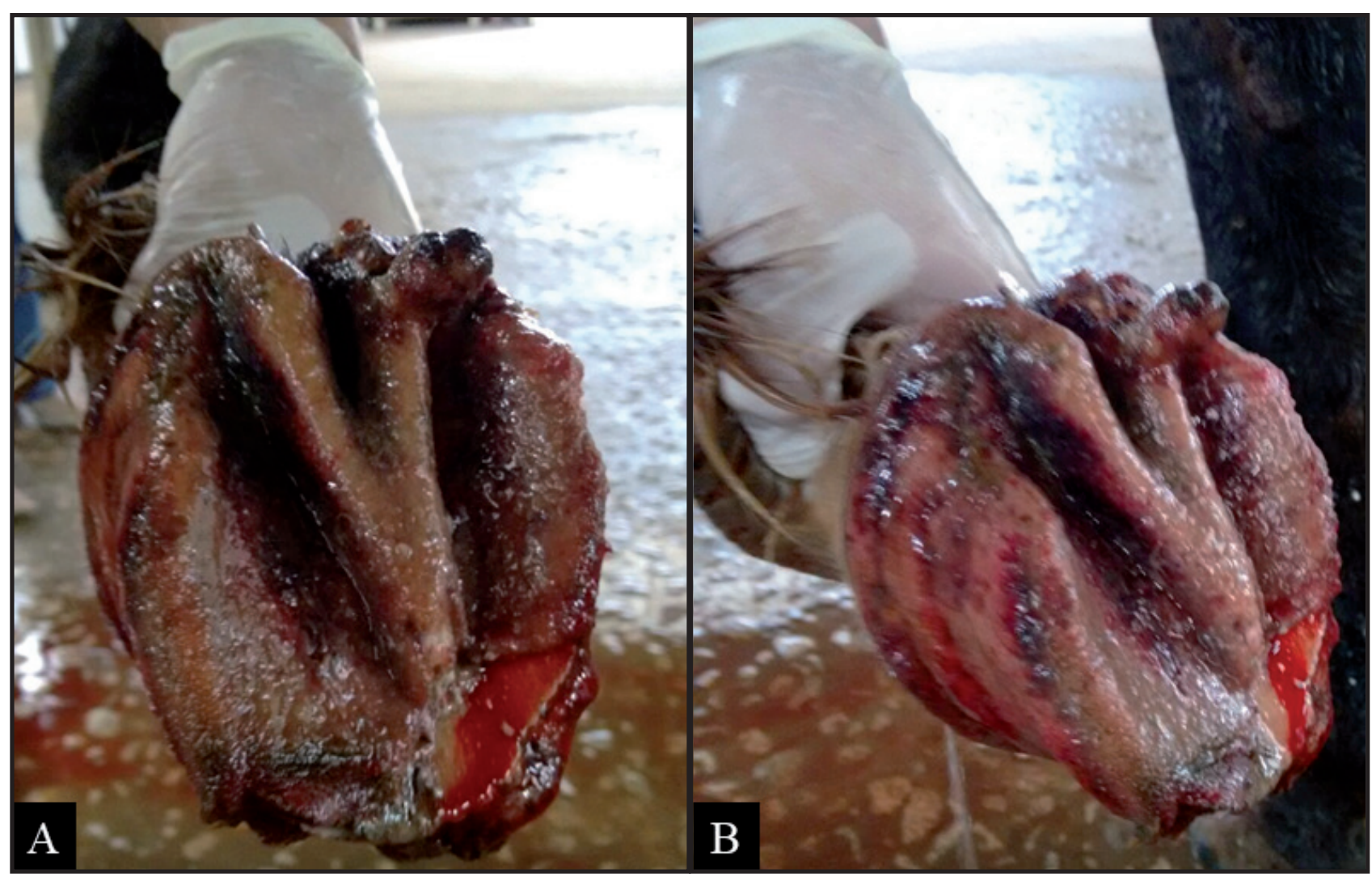

Figure 1. A \& B- Day of admission at the Veterinary Clinical Hospital - UFPel. Complete avulsion of the hoof capsule with exposure of the third phalanx. 


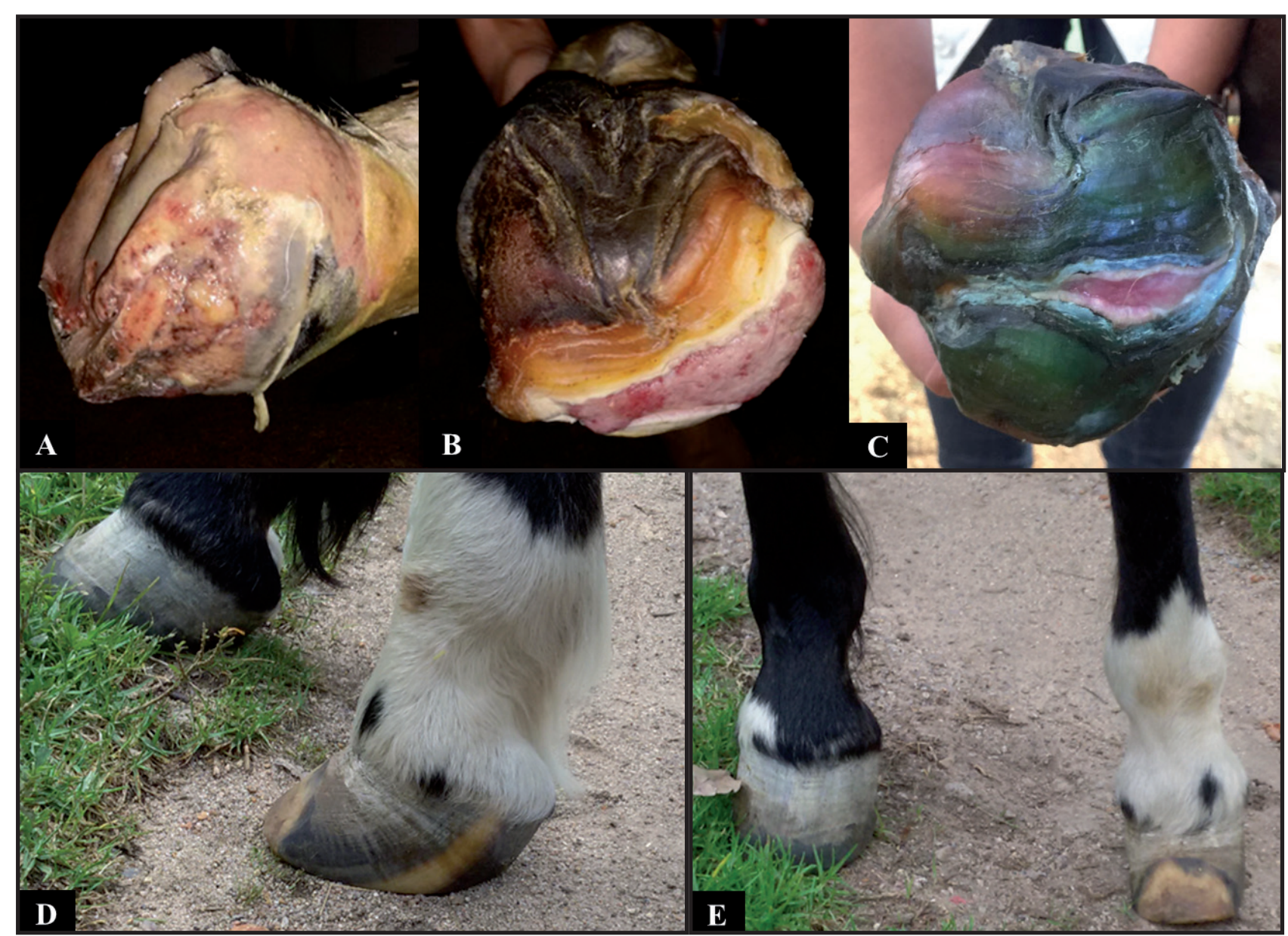

Figure 2. Healing evolution of the wound. A- One month of treatment. B- Two months of treatment. C- Three months of treatment. D \& E- One year after the injury.

Antimicrobial therapy was administered to control possible infection and long-term anti-inflammatory therapy was used to improve horse's well-being through pain control, reduce inflammation and laminar damage [13]. Pentoxifylline was also included in the treatment although its actions are still controversial. It is suggested that this drug inhibits the release of metalloproteinases and decreases blood viscosity by acting on platelets and red blood cells $[13,14]$. Oral supplementation with biotin and methionine, as used in our patient, was also reported to be helpful in hoof injuries [24].

Several conditions can interfere in the recovery of a horse with complete hoof avulsion, as the development of osteomyelitis, the risk of articular involvement leading to septic arthritis, third phalanx fractures and degenerative diseases [20]. In our patient, exposure of the third phalanx and the detachment of a fragment was observed, probably caused by a bone sequestrum. Six months after the injury, radiograph evaluation showed resorption of the distal end of the third phalanx and a dorsal rotation. Rotation probably happens because of the structural arrangement that connects the hoof wall to the coffin bone, which involves insensitive and sensitive laminae that also maintain the phalanx lined up. Exungulation brakes up this connection and rotation of the coffin bone may occur [7]. Even when no complications happen, the horse can remain lame because of the amount of tissue loss [7,19,20].

Support limb laminitis (SLL) is another concern in conditions requiring excessive weight bearing in the contralateral limb [2]. Because of that, the stallion was closely monitored for digital pulses, warmth in the hoof, bulging in the sole and depression at the coronary band during its hospitalization time, however, no alterations were observed. The authors also believe that the horse's behavior of self-protection, which was observed since the beginning of treatment, helped to minimize its chances of developing SLL. Horses that are able to relieve weight from the contralateral limb have a lower risk of developing SLL $[2,16]$. Jackson [11] reported a mare with complete hoof avulsion that was maintained in a sling during 
$10 \mathrm{~h} /$ day to relieve weight from the contralateral limb with no development of SLL.

Alterations in the reproductive tract of the stallion were noticed in the second month of hospitalization, including fluid accumulation in the scrotum, softened consistency of both testicles and lack of libido. Hydrocele and testicular degeneration diagnosis were made presumptively based on the horse's clinical presentation and ultrasound exam. Although semen evaluation is important for diagnosis, attempts for collection were not successful due to lack of libido and response to chemical stimulation. Similarly, biopsy was not performed to avoid postoperative complications [3].

According to Blachard et al. [4] and Blachard et al. [5], softening in the consistency with no necessary alteration in size of testicles may be an indicative of a degenerative process. Low libido in experienced breeding stallions can also be identified in animals with testicular degeneration, musculoskeletal discomfort or intensive pain $[6,12]$. Hydrocele can be a consequence of musculoskeletal injuries and lack of exercise. In addition, a hot climate may also contribute to its formation [3]. This disorder interferes in testicular thermoregu- lation and spermatogenesis, which depending on the duration and severity, may affect semen quality $[1,3]$.

In conclusion, the outcome for exungulation in horses is difficult to predict and several disorders can occur as a consequence. The patient of this report had a complete regrowth of the hoof capsule although a long intensive treatment was necessary to achieve this result. The commitment of the veterinary team and owners was also a key point for a successful outcome. As a consequence, testicles degeneration may happen impairing its function as a stallion.

\section{MANUFACTURERS}

${ }^{1}$ Ouro Fino Saúde Animal Ltda. Cravinhos, SP, Brazil.

${ }^{2}$ Cristália Produtos Químicos Farmacêuticos Ltda. Cotia, SP, Brazil. ${ }^{3}$ Merck Sharp \& Dohme Saúde Animal Ltda. São Paulo, SP, Brazil.

${ }^{4}$ Vansil Indústria, Comércio e Representações Ltda. Dascalvado, SP, Brazil.

${ }^{5}$ Vetpharma Medicamentos Veterinários Ltda. Pelotas, RS, Brazil

${ }^{6}$ Rioquímica S.A. São José do Rio Preto, SP, Brazil.

${ }^{7}$ Vetnil Indústria e Comércio de Produtos Veterinários Ltda. Louveira, SP, Brazil.

Declaration of interest. The authors report no conflicts of interest. The authors alone are responsible for the content and writing of paper.

\section{REFERENCES}

1 Alvarenga M.A. \& Papa F.O. 2009. Principais distúrbios reprodutivos observados em garanhões no Brasil. Revista Brasileira de Reprodução Animal. 6: 204-209.

2 Baxter G.M. 2017. Supporting limb laminitis. In: Belknap J.K. \& Geor R. (Eds). Equine laminitis. Oxford: WileyBlackwell, pp.210-213.

3 Beard W. 2011. Abnormalities of the Testicles. In: McKinnon A.O., Squires E.L. Vaala W.E. \& Varner D.D. (Eds). Equine reproduction. 2nd edn. Ames: Wiley-Blackwell, pp.1161-1665.

4 Blanchard T.L., Johnson L. \& Roser A.J. 2000. Creased germ cell loss rates and poor semen quality in stallions with idiopathic testicular degeneration. Journal of Equine Veterinary of Equine Science. 20(4): 263-265.

5 Blanchard T.L., Johnson L., Varner D.D., Rigby S.L., Brinsko S.P., Love C.C. \& Miller C. 2001. Low daily sperm output per $\mathrm{ml}$ of testis as diagnostic criteria for testicular degeneration in stallions. Journal of Equine Veterinary of Equine Science. 21(1): 33-35.

6 Brinsko S.P., Blanchard T.L., Varner D.D., Schumacher J., Love C.C., Hinrichs K. \& Hartman D. L. 2011. Examination of the Stallion for Breeding Soundness. In: Brinsko S.P., Blanchard T.L., Varner D.D., Schumacher J., Love C.C., Hinrichs K. \& Hartman D.L. (Eds). Manual of Equine Reproduction. 3rd edn. St. Louis: Mosby Elsevier, pp.176-206.

7 Brooks J. \& Pusey A. 2010. Horse anatomy for osteopaths. In: Pusey A., Brooks J. \& Jenks A. (Eds). Osteopathy and the Treatment of Horses. Oxford: Wiley-Blackwell, pp.4-39.

8 Fessler J.F. 1989. Hoof Injuries. Veterinary Clinics of North America: Equine Practice. 5(3): 643-664.

9 Fonteque J.H., Souza A.F., Shade J., Muller T.R. \& Gehrcke M.I. 2017. Exungulation followed by fracture and avulsion of the phalanx in mare. Veterinária e Zootecnia. 24(3): 509-514.

10 Gresti A., Zani D.D., D’arpe L. \& Scandella M.A. 2008. Singular case of traumatic total hoof capsule avulsion. Equine veterinary Education. 20(8): 406-410. 
11 Jackson L.L. 1969. Regrowth of an Equine Hoof Following Traumatic Removal. Iowa State University Veterinarian. 31(2): 44-47.

12 McDonnel S.M. 1999. Libido, Erection, and Ejaculatory Dysfunction in Stallions. Compendium on Continuing Education for the Practicing Veterinarian - North American Edition. 21(3): 263-266.

13 Mitchell C.F., Fugler L.A. \& Eades S.C. 2015. The management of equine acute laminitis. Veterinary Medicine: Research and Reports. 6: 39-47.

14 Moyer W., Schumacher J., Schumacher J. \& Carter G.K. 2008. Are Drugs Effective Treatment for Horses with Acute Laminitis? Proceedings of the Annual Convention of the AAEP. 54: 337-340.

15 Parks A.H. 1999. Equine Foot Wounds: General Principles of Healing and Treatment. Proceedings of the Annual Convention of the AAEP. 45: 180-187.

16 Redden R.F. 2004. Preventing Laminitis in the Contralateral Limb of Horses with Nonweight-Bearing Lameness. Clinical Techniques in Equine Practice. 3: 57-63.

17 Riggs C.M., Proudman C.J., Hughes I. \& Caldwe M. 1995. Management of traumatic, partial hoof avulsion in 2 horses. Equine Veterinary Education. 7(3): 140-144.

18 Ruzickova P., Trencart P. \& Laverty S. 2016. Spontaneous hoof capsule loss following lacerations of the equine distal limb. Equine Veterinary Education. 29(9): 472-477.

19 Schumacher J. \& Stashak T.S. 2008. Management of Wounds of the Distal Extremities. In: Stashak T.S. \& Theoret C.L. (Eds). Equine wound management. 2nd edn. Ames: Wiley-Blackwell, pp.375-425.

20 Stashak T.S. 1989. Management of lacerations and avulsion injuries of the foot and pastern region and hoof wall cracks. Veterinary clinics of North America: Equine practice. 5(1): 195-220.

21 Theoret C.L. 2008. Physiology of Wound Healing. In: Stashak T.S. \& Theoret C.L. (Eds). Equine Wound Management. 2nd edn. Ames: Wiley-Blackwell, pp.5-28.

22 Thomassian A. 2005. Enfermidades dos Cavalos. 4.ed. São Paulo: Livraria Varela, pp.178-179.

23 Turner R.M.O. 2007. Pathogenesis, Diagnosis, and Management of Testicular Degeneration in Stallions. Clinical Techniques in Equine Practice. 6: 278-284.

24 Young J.H. 1988. Hoof wall avulsion: Three case reports. Equine Veterinary Science. 8(6): 420-423. 